\title{
Survival of Five Strains of Shiga Toxigenic Escherichia coli in a Sausage Fermentation Model and Subsequent Sensitivity to Stress from Gastric Acid and Intestinal Fluid
}

\author{
Tone Mari Rode, ${ }^{1}$ Anette McLeod, ${ }^{2}$ Ingrid Måge, ${ }^{2}$ Even Heir, ${ }^{2}$ \\ Lars Axelsson, ${ }^{2}$ and Askild L. Holck ${ }^{2}$ \\ ${ }^{1}$ Nofima AS-Norwegian Institute of Food, Fisheries and Aquaculture Research, P.O. Box 8034, 4068 Stavanger, Norway \\ ${ }^{2}$ Nofima AS-Norwegian Institute of Food, Fisheries and Aquaculture Research, P.O. Box 210, 1431 As, Norway \\ Correspondence should be addressed to Tone Mari Rode; tone.mari.rode@nofima.no
}

Received 31 May 2017; Revised 14 September 2017; Accepted 1 October 2017; Published 29 October 2017

Academic Editor: Barbara H. Iglewski

Copyright (C) 2017 Tone Mari Rode et al. This is an open access article distributed under the Creative Commons Attribution License, which permits unrestricted use, distribution, and reproduction in any medium, provided the original work is properly cited.

\begin{abstract}
The ability of foodborne pathogens to exhibit adaptive responses to stressful conditions in foods may enhance their survival when passing through the gastrointestinal system. We aimed to determine whether Escherichia coli surviving stresses encountered during a model dry-fermented sausage (DFS) production process exhibit enhanced tolerance and survival in an in vitro gastrointestinal model. Salami sausage batters spiked with five $E$. coli isolates, including enterohaemorrhagic $E$. coli strains isolated from different DFS outbreaks, were fermented in a model DFS process $\left(20^{\circ} \mathrm{C}, 21\right.$ days $)$. Control batters spiked with the same strains were stored at $4^{\circ} \mathrm{C}$ for the same period. Samples from matured model sausages and controls were thereafter exposed to an in vitro digestion challenge. Gastric exposure ( $\mathrm{pH} 3$ ) resulted in considerably reduced survival of the E. coli strains that had undergone the model DFS process. This reduction continued after entering intestinal challenge ( $\mathrm{pH} 8)$, but growth resumed after 120 min. When subjected to gastric challenge for $120 \mathrm{~min}$, E. coli that had undergone the DFS process showed about $2.3 \log _{10}$ lower survival compared with those kept in sausage batter at $4^{\circ} \mathrm{C}$. Our results indicated that $E$. coli strains surviving a model DFS process exhibited reduced tolerance to subsequent gastric challenge at low $\mathrm{pH}$.
\end{abstract}

\section{Introduction}

In their natural habitats, Enterobacteriaceae are constantly under assault from different environmental stresses. One of the most frequently encountered hostile conditions is acid stress. While travelling through the gastrointestinal tract, bacteria must endure low $\mathrm{pH}$ conditions in the stomach, and the ability of foodborne pathogens to exhibit adaptive responses to stressful conditions in foods may enhance their survival.

Shiga toxigenic Escherichia coli (STEC) are potential foodborne pathogens. A STEC subgroup, enterohaemorrhagic E. coli (EHEC), is responsible for severe illness in humans and their infectious dose can be as few as 1-100 bacteria [1,2]. EHEC may survive in a range of foods [3] and in the harsh environment of the gastrointestinal tract [4].
Currently, there is no specific treatment for EHEC infections, but supportive therapy is available. The use of conventional antibiotics may worsen Shiga toxin-mediated cytotoxicity [5]. Isolates belonging to the serotype O157:H7 were for many years the most commonly reported agents of EHEC infections, but non-O157:H7 STEC serotypes are increasingly being reported [6-8].

There have been several STEC outbreaks linked to dryfermented sausages (DFS) in which different serotypes were reported as the infectious agent [9-12]. In DFS production, combinations of salt, nitrite, starter culture, lactic acid, low $\mathrm{pH}$, and drying are used as hurdles to inhibit and reduce survival of pathogens [13]. However, studies have shown that in spite of exposure to unfavourable conditions like high $\mathrm{NaCl}$ concentrations and an acidic environment in DFS, E. coli O157:H7 can still survive [14-16]. Although there is variation 
TABLE 1: E. coli isolates used in this study.

\begin{tabular}{lcccccc}
\hline Number & Strain & Serotype & stx1 & stx2 & Source & Comments/reference \\
\hline$(1)$ & E218/02 & O157:H7 & - & + & Dry-fermented sausage & Outbreak Sweden, 2002 $^{*}[11]$ \\
$(2)$ & MF3582 & O157:H- & - & + & Human, clinical & Outbreak Norway 2009 ${ }^{\dagger}$, sorbitol positive [19] \\
$(3)$ & MF2411 & O111:H- & + & + & Semidry-fermented sausage (mettwurst) & Outbreak Australia, 1995 $^{\ddagger}[10]$ \\
$(4)$ & MF2494 & O103:H25 & - & + & Human, clinical & Outbreak Norway 2006 $^{\S}[12]$ \\
$(5)$ & MF2522 & O103:H25 & - & - & Dry-fermented sausage (morr) & Linked to outbreak in Norway, 2006 \\
\hline
\end{tabular}

${ }^{*}$ Kindly received from Dr. S. Löfdahl, Swedish Institute for Infectious Disease Control, Solna, Sweden. ${ }^{\dagger}$ Kindly received from Professor G. Kapperud, Norwegian Institute of Public Health, Oslo, Norway. ${ }^{\ddagger}$ Kindly received from Dr. F. Scheutz, Statens Serum Institut, Copenhagen, Denmark. ${ }^{\S}$ Kindly received from Dr. C. Sekse, Norwegian School of Veterinary Science, Oslo, Norway.

between E. coli strains, certain EHEC strains within the serotypes O157:H7 and O104:H4 are more acid resistant than generic E. coli strains $[17,18]$.

We previously investigated strain dependent reductions of $11 \mathrm{E}$. coli isolates in the DFS production process and during relevant postprocess treatments of DFS [19]. The results showed varying reductions between 1.3 and $2.4 \log _{10} \mathrm{cfu} \mathrm{g}^{-1}$ for the $E$. coli strains during the sausage production process. Different postprocess treatments like storage, heating, and freezing gave additional reductions [19-21]. In the present work, we investigate whether $E$. coli surviving the stresses encountered during a model DFS production process, a tube fermented sausage (TFS) production, would exhibit enhanced tolerance in a gastrointestinal in vitro model. We added EHEC to a popular Norwegian DFS salami batter used in previous investigations [19-22] and, following TFS production, bacteria were exposed to digestion challenge.

\section{Materials and Methods}

2.1. Bacterial Isolates and Growth Conditions. Isolates of E. coli included five outbreak strains of different serotypes with varying stx-profiles, of which four strains were EHEC (Table 1), also used in a previous study by Rode et al. [19]. The strains were maintained at $-80^{\circ} \mathrm{C}$ in tryptic soy broth (TSB; Oxoid, Thermo Fisher Scientific, Basingstoke, UK) supplemented with $20 \%$ glycerol (v/v). Prior to experiments, the E. coli strains were cultured separately in TSB for 16-18 h at $37^{\circ} \mathrm{C}$, in a shaking incubator $(200 \mathrm{rpm})$, and then stored at $4^{\circ} \mathrm{C}$ for $20 \mathrm{~h}$. The strains used in TFS model experiments were added to sausage batter at $10^{6}-10^{7} \mathrm{cfu} \mathrm{g}^{-1}$. Freeze-dried starter culture LS-25 (Lactobacillus sakei and Staphylococcus carnosus in a 1:1 mixture; Gewürzmüller, GmbH, Germany) was resuspended in $0.9 \% \mathrm{NaCl}$, at $4^{\circ} \mathrm{C}$ just prior to adding the starter culture mix to give a total level of $10^{6} \mathrm{cfu} \mathrm{g}^{-1}$ to the batters.

2.2. Tube Fermented Sausage Model. Sausage batter was prepared and fermented in vitro using sterile tubes mainly as described by Heir et al. [20]. In short, the batter contained meat from beef and pork (37.8\% each) and lard from pork (20\%). One bulk of sausage batter was made for the experiments, from which 2-kg packages were vacuum packed and stored at $-20^{\circ} \mathrm{C}$. On the day of sausage production, slightly thawed batter was supplemented with $\mathrm{NaCl}, \mathrm{NaNO}_{2}$, and dextrose to give final concentrations of $3.8 \% \mathrm{NaCl}, 100 \mathrm{ppm}$
$\mathrm{NaNO}_{2}$, and $0.9 \%$ dextrose in the batter. Starter culture LS25 was added to half of the batter. Each of the E. coli strains was individually added to aliquots of batters with and without starter culture. A rotating bowl kitchen machine was used for successively mixing ingredients and bacterial culture into the batter. Aliquots of $30 \mathrm{~g}$ of prepared sausage batter were transferred to 50-ml sterile centrifuge tubes (VWR, Radnor, PA, USA), thereby named "tube fermented sausages (TFS)," and centrifuged at $600 \mathrm{~g}$ for $2 \mathrm{~min}$ to compress the batter and avoid air pockets. The sausage batters containing LS-25 were incubated at $20^{\circ} \mathrm{C}$ for 21 days (fermentation period), followed by storage at $4^{\circ} \mathrm{C}$ for $24 \mathrm{~h}$, while control batters without LS-25 were incubated at $4^{\circ} \mathrm{C}$ for 22 days. The $24 \mathrm{~h}$ cooling period was included to avoid confounding effects caused by differences in temperature for the E. coli cells in the fermented batter compared with the control batter. Using this TFS model, the fermented sausage batters obtained an average water activity $\left(a_{\mathrm{w}}\right)$ of approx. 0.95 [20]. Three productions were performed on different days, each including two parallel batter samples for each $E$. coli isolate. This resulted in three sets of 20 samples ( 2 sample types (fermented and controls), 2 parallels, and 5 strains).

2.3. Microbial and Physiochemical Analyses. At days 0 and 22, samples ( $15 \mathrm{~g}$ ) from matured TFSs and from controls were diluted 1:10 (w/v) in peptone water and homogenized for $1 \mathrm{~min}$ in a stomacher (AES Smasher, AES Chemunex, Bruz, France). Quantification of E. coli was performed using a mechanical spiral plater (Whitley Automatic Spiral Plater, Don Whitley Scientific Ltd., West Yorkshire, UK) on tryptic soy agar (TSA, Oxoid) for $16 \mathrm{~h}$. The TSA plates were incubated at $42.5^{\circ} \mathrm{C}$ to prevent growth of the starter culture and the indigenous flora of the meat batter. Lack of growth of the starter culture and the indigenous flora at this temperature was confirmed in previous studies [19]. Lactic acid bacteria were plated on MRS agar (Oxoid) for $48 \mathrm{~h}$ at $30^{\circ} \mathrm{C}$ to verify the activity of the starter culture. Manual plating was used for samples with low concentrations of bacteria. The detection limit was $20 \mathrm{cfu} \mathrm{g}^{-1}$ batter. Counts of E. coli and starter culture were determined individually from each sample. The probability of isolating confounding indigenous subpopulations of E. coli and other Enterobacteriaceae during the experiment was assumed low because prior studies showed these organisms were present at levels of several $\log _{10}$ values below those of the inoculated STEC strains [19]. Furthermore, the indigenous flora failed to grow under the experimental 
TABLE 2: Digestion challenge model treatments* .

\begin{tabular}{lcc}
\hline Sample & \multicolumn{2}{c}{ Treatment time (min) } \\
& Gastric acid & Intestinal fluid \\
\hline G1 & 1 & 0 \\
G30 & 30 & 0 \\
G30I30 & 30 & 30 \\
G30I120 & 30 & 120 \\
G30I240 & 30 & 240 \\
G120 & 120 & 0 \\
G120I30 & 120 & 30 \\
G120I120 & 120 & 120 \\
G120I240 & 120 & 240 \\
\hline
\end{tabular}

${ }^{*}$ Details are described in Materials and Methods. Digestion challenge model. E. coli isolates surviving a TFS production process were exposed to a model mimicking part of the gastrointestinal tract. G: gastric acid treatment and I: intestinal fluid treatment.

conditions $\left(42.5^{\circ} \mathrm{C}\right)$ used to cultivate the STEC strains (data not shown). Subtyping (serotype) the E. coli isolates recovered from the meat batters was therefore not performed. $\mathrm{pH}$ was measured in duplicate in stomacher-homogenized solutions used for microbiological analysis during fermentation at days $0,1,2,3,5,7,8,10,11,12,14,15,18,20$, and 22 . The $\mathrm{pH}$ was also measured at selected time points during the digestion challenge.

2.4. Digestion Challenge Model. The matured TFSs and controls were exposed to gastric acid (G) and intestinal fluid (I) in an experimental design as listed in Table 2 and illustrated in Figure 1. The gastric acid solution was prepared as described by Molly et al. [23] by mixing the following ingredients: $3.0 \mathrm{gl}^{-1}$ yeast extract; $1.0 \mathrm{gl}^{-1}$ Bacto peptone (Difco, Detroit, USA); $0.5 \mathrm{gl}^{-1}$ cysteine; $0.4 \mathrm{gl}^{-1}$ glucose; $4.0 \mathrm{gl}^{-1}$ porcine mucin; $0.08 \mathrm{gl}^{-1} \mathrm{NaCl} ; 0.4 \mathrm{gl}^{-1} \mathrm{NaHCO}_{3}$; $0.04 \mathrm{gl}^{-1} \quad \mathrm{~K}_{2} \mathrm{HPO}_{4} ; \quad 0.04 \mathrm{gl}^{-1} \quad \mathrm{KH}_{2} \mathrm{PO}_{4} ; \quad 0.008 \mathrm{gl}^{-1}$ $\mathrm{CaCl}_{2} \cdot 2 \mathrm{H}_{2} \mathrm{O} ; 0.008 \mathrm{gl}^{-1} \quad \mathrm{MgSO}_{4} \cdot 7 \mathrm{H}_{2} \mathrm{O} ; 1.0 \mathrm{gl}^{-1} \quad$ xylan; $3.0 \mathrm{gl}^{-1}$ soluble starch; $2.0 \mathrm{gl}^{-1}$ pectin; and $1 \mathrm{mll}^{-1}$ Tween 80. The solution was autoclaved and cooled, and then $3 \mathrm{gl}^{-1}$ pepsin from porcine stomach mucosa (Sigma-Aldrich, Steinheim, Germany) was added. By using $10 \mathrm{moll}^{-1} \mathrm{HCl}$, the $\mathrm{pH}$ was adjusted to 2.0. The intestinal fluid solution was prepared fresh by mixing $0.25 \mathrm{gl}^{-1}$ porcine pancreatin (Sigma-Aldrich) and $3 \mathrm{gl}^{-1}$ porcine bile and was filtrated $(0.45 \mu \mathrm{m}$, Nalgene, Rochester, USA) before use [24]. Samples were kept at $37^{\circ} \mathrm{C}$ during the digestion challenge experiments. Tube fermented sausage batters $(15 \mathrm{~g})$ were transferred to separate stomacher bags, diluted $1: 10$ by addition of $135 \mathrm{ml}$ gastric acid solution, and stomached. Samples were incubated for 1, 30, and 120 min simulating different duration of exposure to gastric acid (samples G1, G30, and G120, resp.; Figure 1 and Table 2). Furthermore, $20 \mathrm{ml}$ intestinal fluid solution was added to $20 \mathrm{ml}$ samples of G30 and G120 (1:1), and $\mathrm{pH}$ was adjusted to 8 using $5 \mathrm{moll}^{-1} \mathrm{NaOH}$. Sampling from G30 and G120 tubes to which intestinal fluid was added was then performed after 30,120 , and $240 \mathrm{~min}$ (I30, I120, and I240, resp.; Table 2). The G1 samples were used to measure

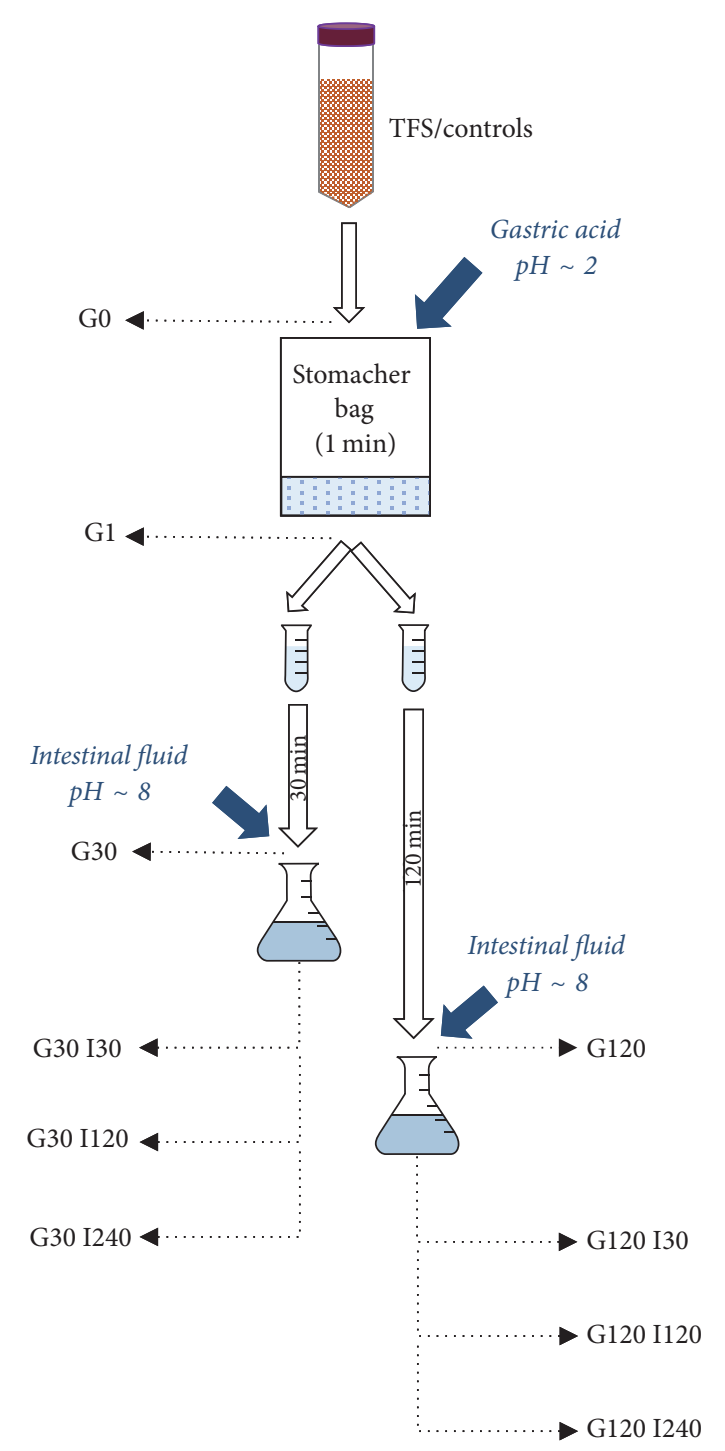

FIGURE 1: Flow chart illustrating the experimental setup. TFS (tube fermented sausage) and control batter ( $15 \mathrm{~g}$ ) were transferred to separate stomacher bags, diluted 1:10 in gastric acid solution, and stomached for $1 \mathrm{~min}$. Samples were transferred to tubes and incubated for 1, 30, and 120 min (samples G1, G30, and G120, resp.). Furthermore, intestinal fluid solution was added to samples after 30 and $120 \mathrm{~min}(1: 1)$. Sampling from G30 and G120 tubes was performed after 30,120 , and $240 \mathrm{~min}$. Each experiment was repeated three times and included 2 sample types (fermented and controls) $\times$ 2 parallels $\times 5$ E. coli strains. A total of $60(3 \times 20)$ samples were included for the digestion challenge study.

the immediate response to gastric acid exposure. After the digestion challenge experiments, samples were immediately subjected to microbial analysis (described above). Control batters were treated in a similar matter as the TFS.

2.5. Statistical Analysis. E. coli reductions between time points $t_{0}$ and $t_{1}$ were calculated as $\log _{10}\left(C_{t 0} / C_{t 1}\right)$, where $C$ is the counts of $E$. coli $\left(\mathrm{cfu} \mathrm{g}^{-1}\right)$. Analysis of variance (ANOVA) was used to determine statistically significant differences in E. coli reductions in various stages of the digestion challenge. 
TABLE 3: Reduction of E. coli during gastric treatment*

\begin{tabular}{|c|c|c|c|c|}
\hline \multirow{2}{*}{ Fermentation status } & \multirow{2}{*}{ Strain } & \multicolumn{3}{|c|}{ Gastric treatment time (min) } \\
\hline & & 1 & 30 & 120 \\
\hline \multirow{5}{*}{ TFS } & $(1)$ & $1.26(0.20)$ & $2.03(0.26)$ & $2.87(0.63)$ \\
\hline & (2) & $0.76(0.30)$ & $2.12(0.27)$ & $2.88(0.32)$ \\
\hline & (3) & $1.04(0.50)$ & $2.05(0.60)$ & $2.56(0.65)$ \\
\hline & (4) & $0.88(0.48)$ & $2.22(0.24)$ & $3.14(0.14)$ \\
\hline & (5) & $1.14(0.35)$ & $1.84(0.64)$ & $3.45(0.46)$ \\
\hline \multirow{5}{*}{ Control } & (1) & $0.32(0.17)$ & $0.37(0.16)$ & $0.71(0.13)$ \\
\hline & $(2)$ & $0.06(0.02)$ & $0.14(0.09)$ & $0.49(0.05)$ \\
\hline & (3) & $0.13(0.13)$ & $0.35(0.12)$ & $0.69(0.24)$ \\
\hline & (4) & $0.32(0.08)$ & $0.38(0.18)$ & $0.75(0.15)$ \\
\hline & $(5)$ & $0.30(0.18)$ & $0.51(0.31)$ & $1.02(0.20)$ \\
\hline
\end{tabular}

${ }^{*}$ The numbers are average reductions of $\log _{10}$ cfu values compared with before gastric treatment. Standard deviation values are shown in brackets.

(1) Gastric Treatments. E. coli reductions between matured TFSs or controls $\left(t_{0}=\mathrm{G} 0 /\right.$ day 22$)$ and gastric acid incubation time $\left(t_{1}=\mathrm{G} 1, \mathrm{G} 30\right.$, or G120 $\left.\mathrm{min}\right)$ were analyzed with respect to the experimental factors "strain," "fermentation," and "gastric acid incubation time."

(2) Intestinal Treatments. E. coli reductions between end of gastric treatments $\left(t_{0}=\right.$ G30 or G120) and intestinal fluid incubation time $\left(t_{1}=\mathrm{I} 30\right.$, I120, or I240 $\left.\mathrm{min}\right)$ were analyzed with respect to the experimental factors "strain," "fermentation," "gastric acid incubation time," and "intestinal fluid incubation time."

(3) Digestion Time Lapse. For each of the four groups "fermented-G30," "fermented-G120," "control-G30," and "control-G120," the differences between subsequent time points in the digestion process were analyzed.

In all cases, a nested mixed model was used to calculate the ANOVA. Tubes (modelled as a random factor) are nested within fixed factors "strain" and "fermentation." The factors "gastric acid incubation time" and "intestinal fluid incubation time" are within-tube fixed factors. Models included main effects and two-level interaction effects. The analyses were performed using MATLAB (R2014b, The Mathworks, Inc., Natick, USA, https://www.mathworks.com) and Minitab ${ }^{\circledR}$ Statistical Software (version 17.2.1, http://www.minitab.com).

\section{Results}

3.1. Reduction of E. coli in the TFS Model. Results from matured TFS, batter with starter culture fermented at $20^{\circ} \mathrm{C}$ for 21 days, and $4^{\circ} \mathrm{C}$ controls are presented in Figure 2. The TFS production process resulted in a $0.7 \log _{10} \mathrm{cfu} \mathrm{g}^{-1}$ average reduction of $E$. coli, ranging from 0.5 to $0.8 \log _{10} \mathrm{cfu} \mathrm{g}^{-1}$, a small difference of only $0.3 \log _{10}$ between the most and least resistant isolates, 2 and 5, respectively. During the 21-day sausage production period, the $\mathrm{pH}$ rapidly dropped from 5.7 to 4.6 within two days and then remained stable. At the end of the period, the average $\mathrm{pH}$ was $4.63 \pm 0.05$ (range 4.57-4.71). For the corresponding $4^{\circ} \mathrm{C}$ controls, lower E. coli

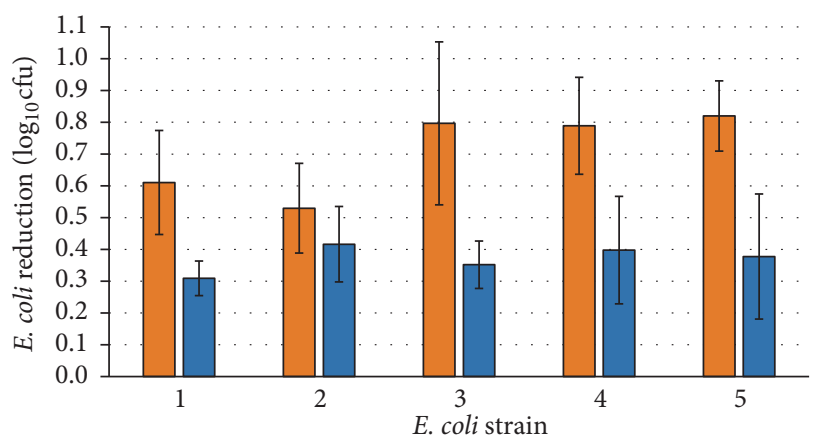

FIGURE 2: Reduction of E. coli in a TFS model. Salami batter with starter culture fermented at $20^{\circ} \mathrm{C}$ for 21 days giving matured sausages (orange bars) and meat batter controls without starter culture held at $4^{\circ} \mathrm{C}$ (blue bars) are shown. Isolates are numbered according to Table 1.

reductions were observed, ranging from 0.3 to $0.4 \log _{10}$, and the $\mathrm{pH}$ remained at 5.7 for 14 days before slowly declining to an average $\mathrm{pH}$ of $4.97 \pm 0.17$ at the end of the period.

3.2. Reduction of E. coli during Digestion Challenge. Reductions of $E$. coli in the TFS samples were significantly larger $(p<0.001)$ during gastric acid treatments compared with controls (Figure 3, Tables 2 and 3). Already after 1 min (G1), the five E. coli strains showed an average reduction of $1.0 \log _{10}$ (range $0.8-1.3$ ) in the TFS samples. Continued reduction was seen after $30 \mathrm{~min}$, with an average reduction of $2.1 \log _{10}$ (range 1.8-2.2), which after $120 \mathrm{~min}$ averaged $3.0 \log _{10}$. For the $4^{\circ} \mathrm{C}$ controls, the average reduction was only $0.2 \log _{10}$ after $1 \mathrm{~min}$ of gastric acid treatment. Although at a low level, continued reductions were thereafter seen both from 1 to $30 \mathrm{~min}$ and from 30 to $120 \mathrm{~min}$ of gastric acid treatment, with $\log _{10}$ values of 0.4 and $0.7 \log _{10}$, respectively. The $\mathrm{pH}$ during gastric challenge ranged from 2.88 to 3.21 for all TFS and controls, where the TFS samples had an average $\mathrm{pH}$ of $3.10 \pm 0.12$, and the control samples had marginally lower value of $3.01 \pm 0.11(p<0.05)$.

For the TFS samples exposed to the longest acid stress treatment lasting for $120 \mathrm{~min}$ (G120), continued reduction 
TABLE 4: Reductions of E. coli during intestinal treatment*

\begin{tabular}{|c|c|c|c|c|c|c|c|}
\hline \multirow{2}{*}{$\begin{array}{l}\text { Fermentation } \\
\text { status }\end{array}$} & \multirow[t]{2}{*}{ Strain } & \multicolumn{3}{|c|}{$\begin{array}{l}\text { Intestinal treatment time after } 30 \text { min gastric } \\
\text { treatment }(\mathrm{min})\end{array}$} & \multicolumn{3}{|c|}{$\begin{array}{l}\text { Intestinal treatment time after } 120 \text { min gastric } \\
\text { treatment (min) }\end{array}$} \\
\hline & & 30 & 120 & 240 & 30 & 120 & 240 \\
\hline \multirow{5}{*}{ TFS } & (1) & $0.42(0.38)$ & $0.70(0.26)$ & $-0.33(0.36)$ & $0.76(0.16)$ & $1.03(0.79)$ & $0.18(0.64)$ \\
\hline & (2) & $0.37(0.34)$ & $0.58(0.22)$ & $-0.91(0.51)$ & $1.23(0.14)$ & $1.46(0.16)$ & $1.00(0.86)$ \\
\hline & (3) & $0.41(0.22)$ & $0.50(0.22)$ & $-1.00(0.18)$ & $1.05(0.16)$ & $0.85(0.46)$ & $-0.13(0.35)$ \\
\hline & $(4)$ & $0.26(0.38)$ & $0.40(0.39)$ & $-0.49(0.43)$ & $1.27(0.53)$ & $1.23(0.49)$ & $0.69(0.90)$ \\
\hline & (5) & $0.80(0.76)$ & $0.95(1.35)$ & $-0.01(1.28)$ & $1.30(0.20)$ & $1.46(0.30)$ & $0.79(0.43)$ \\
\hline \multirow{5}{*}{ Control } & (1) & $0.25(0.19)$ & $0.14(0.14)$ & $-1.52(0.28)$ & $0.18(0.22)$ & $0.20(0.14)$ & $-0.86(0.34)$ \\
\hline & (2) & $0.18(0.24)$ & $-0.13(0.14)$ & $-1.83(0.09)$ & $0.22(0.28)$ & $0.26(0.12)$ & $-1.16(0.55)$ \\
\hline & (3) & $0.20(0.20)$ & $0.03(0.18)$ & $-1.69(0.30)$ & $0.15(0.42)$ & $0.33(0.36)$ & $-0.94(0.46)$ \\
\hline & $(4)$ & $0.20(0.08)$ & $-0.04(0.09)$ & $-1.84(0.13)$ & $0.18(0.16)$ & $0.20(0.10)$ & $-1.32(0.16)$ \\
\hline & $(5)$ & $0.21(0.18)$ & $0.13(0.07)$ & $-1.27(0.44)$ & $0.54(0.41)$ & $0.42(0.12)$ & $-0.66(0.49)$ \\
\hline
\end{tabular}

${ }^{*}$ The numbers are average reductions of $\log _{10}$ cfu values compared with after gastric treatment. Standard deviation values are shown in brackets.

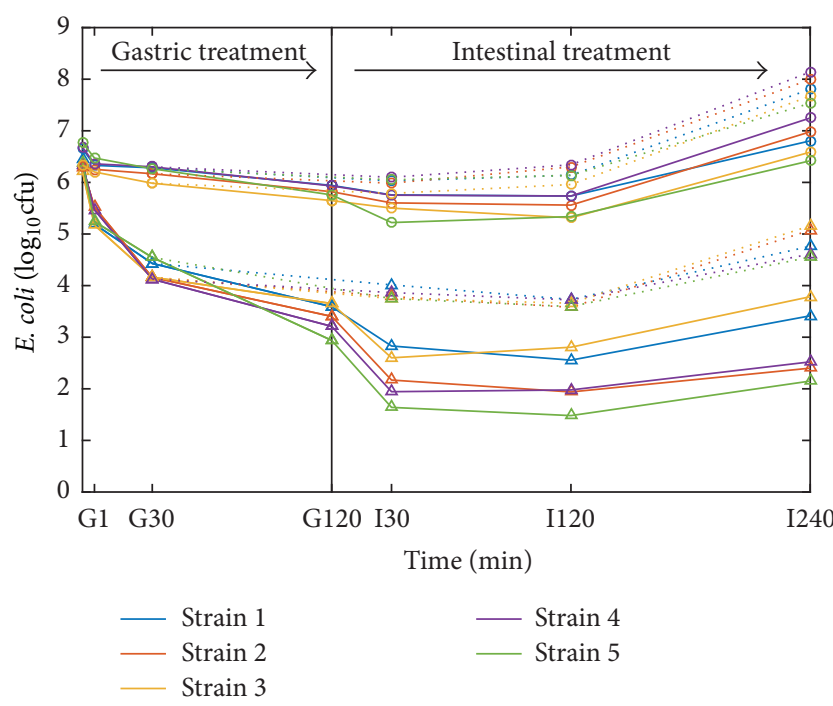

FIGURE 3: Counts of E. coli during digestion challenge. Salami batter with starter culture fermented at $20^{\circ} \mathrm{C}$ for 21 days and thereafter stored for $24 \mathrm{~h}$ at $4^{\circ} \mathrm{C}(\triangle)$ and control batters without starter culture which were held at $4^{\circ} \mathrm{C}$ for 22 days $(O)$ are shown. Exposure of samples to gastric acid (gastric treatment; G) for 30 or $120 \mathrm{~min}$ and subsequently to intestinal fluid (intestinal treatment; I) for $240 \mathrm{~min}$ is according to Table 2. Dotted and continuous lines represent samples exposed to 30 and $120 \mathrm{~min}$ of gastric treatments, respectively, before intestinal treatment. Average values from three independent experiments with two parallels each are given, and strains are numbered according to Table 1 .

was seen until $30 \mathrm{~min}$ in intestinal fluid $(p<0.001)$ (Table 4$)$, reaching an average of $4.1 \log _{10}$ (range 3.6-4.7). After 30 and $120 \mathrm{~min}$ in intestinal fluid, cell counts remained unchanged $(p>0.05)$. Furthermore, the bacterial cells seemed to recover, as growth was observed from 120 to $240 \mathrm{~min}$ in intestinal fluid, and the average reduction was $3.5 \log _{10}$ (range 2.4-4.2) at the end of the experiment. E. coli in the $4^{\circ} \mathrm{C}$ controls exposed to gastric acid for $120 \mathrm{~min}$ showed an average reduction of $1.0 \log _{10}$ (range $0.7-1.6$ ) after $30 \mathrm{~min}$ in intestinal fluid $(p<0.001)$. No further reduction was seen between 30 and $120 \mathrm{~min}$ in intestinal fluid $(p>0.05)$, and the average reduction remained $1.0 \log _{10}$ (range $0.8-1.4$ ) after $120 \mathrm{~min}$. From 30 to $240 \mathrm{~min}$ in intestinal fluid, the bacterial cells in the controls seemed to recover and started growing. Specifically, from 120 to $240 \mathrm{~min}$ in intestinal fluid, the cells multiplied and reached higher numbers than before digestion challenge $(p<0.001)$.

E. coli in the TFS samples exposed to the shorter gastric acid treatment lasting for $30 \mathrm{~min}$ (G30) showed only slight additional reduction after subsequent $30 \mathrm{~min}$ in intestinal fluid ( $p<0.001$ ), with an average reduction of $2.5 \log _{10}$ (range 2.4-2.6). Between 30 and $120 \mathrm{~min}$ in intestinal fluid, no further reduction occurred $(p>0.05)$, and the bacterial cells seemed to recover. From 120 to $240 \mathrm{~min}$ in intestinal fluid, there was an increase in bacterial numbers and the average reduction was only $1.5 \log _{10}$ (range 1.1-1.8) at the end of the experiment. For E. coli in the $4^{\circ} \mathrm{C}$ controls exposed to acid stress for $30 \mathrm{~min}$, a small reduction was seen after subsequent $30 \mathrm{~min}$ in intestinal fluid $(p<0.01)$, with an average of $0.6 \log _{10}$ (range 0.3-0.7). From 30 and $120 \mathrm{~min}$ in intestinal fluid, the cells recovered and started to grow, and from 120 to $240 \mathrm{~min}$, cell counts were higher than before digestion challenge.

The fermentation process was found to have the largest impact on reductions of $E$. coli in the gastric acid treatment (Table 5). In other words, bacterial reduction differed the most between matured TFSs and corresponding controls. Changing the duration of gastric acid treatment also had a large effect, and there was an interaction effect between fermentation and gastric acid treatment duration. The duration of intestinal fluid treatment had largest effect on bacterial reduction in the intestine (Table 6). There were also individual effects of fermentation and of gastric incubation time and an interaction effect between treatment duration with intestinal fluid and fermentation.

ANOVA on the results from matured TFSs and batter controls separately demonstrated statistically significant variations in bacterial reductions between the different $E$. coli 
TABLE 5: ANOVA of E. coli reductions during gastric acid treatment in a TFS model ${ }^{\dagger}$.

\begin{tabular}{lcc}
\hline Source & $\begin{array}{c}\text { Degrees of } \\
\text { freedom }\end{array}$ & $\begin{array}{c}\text { Explained } \\
\text { variance }\end{array}$ \\
\hline Strain $(S)$ & 4 & 1.0 \\
Fermentation $(F)$ & 1 & $56.3^{*}$ \\
Gastric acid incubation time $(G)$ & 2 & $22.9^{*}$ \\
$S \times F$ & 4 & 0.1 \\
$S \times G$ & 8 & 1.0 \\
$F \times G$ & 2 & $8.1^{*}$ \\
Tube (within $F$ and $S$ ) & 50 & $6.0^{*}$ \\
Tube $\times G$ (within $F$ and $S)$ & 100 & 3.8 \\
Error & 8 & 0.7 \\
$R_{\text {adjusted }}^{2}$ & & 0.83 \\
\hline
\end{tabular}

${ }^{\dagger}$ Main effects and two-factor interactions are included. The factor tube is modelled as random, while all other factors are considered fixed. Numbers in the table correspond to explained variances (sum-of-squares as $\%$ of total sum-of-squares), and significant effects on $1 \%$ level are marked by $*$. The model is based on gastric acid treatments for 1, 30, and $120 \mathrm{~min}$ (G1, G30, and G120, resp.; Table 2). Other factors are fermentation $\left(4\right.$ or $\left.20^{\circ} \mathrm{C}\right)$ and strain (E. coli isolates, Table 1).

TABle 6: ANOVA of E. coli reductions during intestinal fluid treatments in a TFS model ${ }^{\dagger}$.

\begin{tabular}{lcc}
\hline Source & $\begin{array}{c}\text { Degrees of } \\
\text { freedom }\end{array}$ & $\begin{array}{c}\text { Explained } \\
\text { variance }\end{array}$ \\
\hline Strain $(S)$ & 4 & 2.2 \\
Fermentation $(F)$ & 1 & $21.6^{*}$ \\
Gastric incubation time $(G)$ & 1 & $8.3^{*}$ \\
Intestine incubation time $(I)$ & 2 & $35.8^{*}$ \\
$S \times F$ & 4 & 0.8 \\
$S \times G$ & 4 & 0.7 \\
$S \times I$ & 8 & 0.5 \\
$F \times G$ & 1 & 1.5 \\
$F \times I$ & 2 & $2.7^{*}$ \\
$G \times I$ & 2 & $1.4^{*}$ \\
Tube (within $F$ and $S$ ) & 50 & 8.2 \\
Tube $\times G$ (within $F$ and $S$ ) & 50 & 7.5 \\
Tube $\times I$ (within $F$ and $S$ ) & 100 & $4.7^{*}$ \\
Error & 130 & 4.1 \\
$R^{2}$ adjusted & & 0.89 \\
\hline
\end{tabular}

${ }^{\dagger}$ Main effects and two-factor interactions are included. The factor tube is modelled as random, while all other factors are considered fixed. Numbers in the table correspond to explained variances (sum-of-squares as \% of total sum-of-squares), and significant effects on $1 \%$ level are marked by $*$. The model is based on intestinal treatments for 30, 120, and $240 \mathrm{~min}$ (I30, I120, and I240, resp.; Table 2) after 30 or 120 min of gastric acid exposure (G30 and G120, resp.; Table 2). Other factors are fermentation $\left(4\right.$ or $\left.20^{\circ} \mathrm{C}\right)$ and strain (E. coli isolates, Table 1).

strains, though the variations were small (results not shown). Considering gastric acid treatments, E. coli reductions in controls treated for $120 \mathrm{~min}$ showed a $0.5 \log _{10}$ difference between strains 2 and 5 . The largest strain variation was observed for the TFS samples exposed to gastric acid for
$120 \mathrm{~min}$ followed by $240 \mathrm{~min}$ in intestinal fluid (G120I240), where a $1.8 \log _{10}$ difference was seen between strains 3 and 5 (reductions of $2.4 \log _{10}$ and $4.2 \log _{10}$, resp.). Furthermore, there were no strain differences for the TFSs exposed to gastric acid for $30 \mathrm{~min}$ and subsequently intestinal fluid for $240 \mathrm{~min}$ (G30I240). For the corresponding controls exposed to gastric acid for $30 \mathrm{~min}$ followed by $240 \mathrm{~min}$ in intestinal fluid (G30I240), the strains grew well and average counts ended with $1.7 \log _{10}$ higher than before the intestinal challenge, where a statistically significant difference was seen in strains 2,3 , and 4 recovering better than strain 5 .

\section{Discussion}

We aimed to examine how E. coli outbreak strains of different serotypes subjected to a fermented sausage production process survive a subsequent gastric and intestinal challenge. Our hypothesis was that strains adapted to acid during the production process might show enhanced survival in digestion challenge. The effect of fermentation $\left(\right.$ at $20^{\circ} \mathrm{C}$ ) and low $\mathrm{pH}$ (4.6) in a fermented sausage model (tube fermented sausages, TFS) on the survival of $E$. coli was compared with bacterial survival in sausage batter stored at $4^{\circ} \mathrm{C}$ (control). In previous studies, parameters of tube fermented sausages were similar to those of conventional fermented sausages containing the same meat matrix with regard to $\mathrm{NaCl}$ concentration, $\mathrm{pH}$ development, and lactic acid production [20,25]. Thus we consider the TFS model useful for the gastrointestinal challenge experiments even though very limited drying occurs during the tube fermentation process.

The resulting data from TFSs and control batters exposed to the in vitro digestion challenge model showed a marked difference in E. coli survival between the two. ANOVA models were useful for determining the statistically significant effects on $E$. coli reduction. Contrary to what we initially expected, $E$. coli undergoing TFS production at $20^{\circ} \mathrm{C}$ and $\mathrm{pH} 4.6$ showed higher reduction when subjected to gastric challenge (2.1 and $3.0 \log _{10}$ after 30 and $120 \mathrm{~min}$, resp.), compared with E. coli in control sausage batter at $4^{\circ} \mathrm{C}$ and $\mathrm{pH} 5.0$ (Figure 2). The fermented meat samples were diluted tenfold with simulated gastric juice. Although diluted, the samples still contained a low amount of lactic acid. Since the $\mathrm{pH}$ was low, the majority of this lactic acid would be in undissociated form able to penetrate the cell membrane and contribute to acid stress. Control samples stored at $4^{\circ} \mathrm{C}$ also underwent a slow spontaneous fermentation process from day 14 and reached a $\mathrm{pH}$ of 5.0 by day 22; thus undissociated lactic acid would also present in these samples during the gastric challenge. Since the fermented samples and the controls had similar $\mathrm{pH}$ during gastric challenge and both contained undissociated lactic acid, the enhanced reduction in survival is likely caused by the influence of the overall fermentation process for the $20^{\circ} \mathrm{C}$ matured TFS. After incubation in intestinal fluid, reduction of bacterial cells continued up to $30 \mathrm{~min}$, with a more pronounced reduction for the cells that had undergone the TFS process. Likely, this reflects that increasing cellular damage was inflicted with increasing duration of the gastric acid exposure. However, the lag time before growth commenced appeared to be fairly similar for cells surviving for 
30 and $120 \mathrm{~min}$ in the acidic environment, and cells grew well in all samples after recovery, regardless of previous treatment.

In contrast to our findings, Naim et al. [24] previously demonstrated that E. coli O157:H7 isolates surviving a dryfermented sausage process acquired a strong protective effect and survived in the digestive fluids. The average $\mathrm{pH}$ differed between their findings and ours. During gastric acid treatment, the $\mathrm{pH}$ in our study was 3.05, whereas Naim et al. [24] demonstrated a $\mathrm{pH}$ of 3.20. Moreover, their target $\mathrm{pH}$ after fermentation was 4.9 , compared with 4.6 in our study. This $\mathrm{pH}$ difference likely account for some of the differences seen in E. coli survival between the two studies. A fermentation of summer sausages to $\mathrm{pH} 4.6$ and $\mathrm{pH} 5.0$, followed by mild heat treatment, was previously shown by Calicioglu et al. [26] to give a reduction of E. coli O157:H7 of $\geq 7.0$ and $3.2 \log _{10}$, respectively. This could indicate that even small changes in the final $\mathrm{pH}$ in a fermented product have a large impact on bacterial survival when exposed to further stress. When $\mathrm{pH}$ was increased to 8 (intestinal challenge), there was an additional reduction before a recovery and growth initiation was observed for the strains in our study. This recovery pattern was partly different from findings by Naim et al. [24] where E. coli remained stable after the passage to the intestinal challenge. However, in both studies, growth was observed after $120 \mathrm{~min}$.

Several reports have stated that different E. coli isolates vary widely in their ability to survive low $\mathrm{pH}$ conditions $[15,27,28]$, while others have claimed that O157 strains have higher acid tolerance compared with strains of other $E$. coli serogroups $[17,27,29,30]$. In our present study, which included both O157:H7 and O157:H- and outbreak isolates from serogroups $\mathrm{O} 103$ and O111, the non-O157 isolates had the same reduction profile as the $\mathrm{O} 157$ isolates. Our former investigation also demonstrated similar survival of the O157 and non-O157 isolates after storage in DFS at 4,16 , and $20^{\circ} \mathrm{C}$ for 1, 2, and 3 months [19]. Bergholz and Whittam [29] studied the impact of acidity using STEC strains including O157:H7, O26:H11, and O111:H8 inoculated in apple juice stored at 4 and $22^{\circ} \mathrm{C}$ for $24 \mathrm{~h}$ prior to gastric challenge. The prestorage at $4^{\circ} \mathrm{C}$ resulted in higher bacterial survival than prestorage at $22^{\circ} \mathrm{C}$, and the mean survival rate of the $\mathrm{O} 157: \mathrm{H} 7$ strains was more than three times higher compared with O26 and O111 isolates. Storage at low temperature in our present study also gave higher survival of $E$. coli at low $\mathrm{pH}$, although there was no higher tolerance of the tested $E$. coli serogroup $\mathrm{O} 157$ strains. In a large meta study by McQuestin et al. [31], temperature was stated to have the largest impact on inactivation of $E$. coli during fermentation in meat.

When bacteria are exposed to stress, they can enter a viable, nonculturable condition. Injured cells can enter this state. Severe stress as a consequence of exposure to food matrices and high or low temperature can lead to increased cell injury and decreased bacterial survival. The reduction numbers from the TFSs are based on growth on agar plates at $42.5^{\circ} \mathrm{C}$; thus it cannot be ruled out that some injured cells might have had difficulties in growing at this temperature. However, in our previous investigations, some of the strains were plated under various conditions for recovering injured cells, but we did not discover any viable, nonculturable cells [19].

\section{Conclusions}

We have shown that $E$. coli surviving a model tube fermented sausage (TFS) process exhibit reduced tolerance to low $\mathrm{pH}$ in a subsequent digestion challenge model due to the extended exposure to acidic conditions and storage at ambient temperature during sausage fermentation. The E. coli $\mathrm{O} 157$ isolates tested had a survival pattern similar to the non-O157 isolates when exposed to the environment in the digestive system, but the limited number of strains and their origins being connected to DFS restrict us from concluding whether they have similar abilities to endure acid stress. Investigating a larger selection of strains of various origins and serotypes could aid in determining this. Further studies should also include various sausage fermentation and digestion challenge conditions to widen the knowledge of the role of DFS process parameters in reducing microbial food safety risks of this type of products.

\section{Conflicts of Interest}

The authors declare that they have no conflicts of interest.

\section{Acknowledgments}

The authors thank Birgitta Baardsen for excellent technical assistance. This work was funded by the Research Council of Norway (Projects 178230/I10, 221663/F40, and 224921/F40), Research for Levy on Agricultural Products, The Norwegian Research Fees Fund for Agricultural Goods, Nortura, The Norwegian Independent Meat and Poultry Association, and NHO Mat \& Bio.

\section{References}

[1] J. L. Jaeger and D. W. Acheson, "Shiga toxin-producing Escherichia coli," Current Infectious Disease Reports, vol. 2, no. 1, pp. 61-67, 2000.

[2] P. M. Griffin, "Epidemiology of Shiga toxin-producing Escherichia coli infections in humans in the United States," in Escherichia coli O157:H7 and Other Shiga Toxin-Producing E. coli Strains, J. B. Kaper and A. D. O’Brien, Eds., pp. 15-22, ASM Press, Washington, DC, USA, 1988.

[3] M. C. Erickson and M. P. Doyle, "Food as a vehicle for transmission of Shiga toxin-producing Escherichia coli," Journal of Food Protection, vol. 70, no. 10, pp. 2426-2449, 2007.

[4] S. B. Price, J. C. Wright, F. J. DeGraves, M.-P. Castanie-Cornet, and J. W. Foster, "Acid resistance systems required for survival of Escherichia coli O157:H7 in the bovine gastrointestinal tract and in apple cider are different," Applied and Environmental Microbiology, vol. 70, no. 8, pp. 4792-4799, 2004.

[5] P. N. Goldwater and K. A. Bettelheim, "Treatment of enterohemorrhagic Escherichia coli (EHEC) infection and hemolytic uremic syndrome (HUS)," BMC Medicine, vol. 10, article 12, 2012.

[6] J. T. Brooks, E. G. Sowers, J. G. Wells et al., "Non-O157 Shiga toxin-producing Escherichia coli infections in the United States, 
1983-2002," The Journal of Infectious Diseases, vol. 192, no. 8, pp. 1422-1429, 2005.

[7] E. C. Mathusa, Y. Chen, E. Enache, and L. Hontz, "Non-O157 Shiga toxin-producing Escherichia coli in foods," Journal of Food Protection, vol. 73, no. 9, pp. 1721-1736, 2010.

[8] M. C. Pearce, J. Evans, I. J. McKendrick et al., "Prevalence and virulence factors of Escherichia coli serogroups O26, O103, O111 and $\mathrm{O} 145$ shed by cattle in Scotland," Applied and Environmental Microbiology, vol. 72, no. 1, pp. 653-659, 2006.

[9] S. Ethelberg, B. Smith, M. Torpdahl et al., "Outbreak of nonO157 shiga toxin producing Escherichia coli infection from consumption of beef sausage," Clinical Infectious Diseases, vol. 48, no. 8, pp. e78-e81, 2009.

[10] A. W. Paton, R. M. Ratcliff, R. M. Doyle et al., "Molecular microbiological investigation of an outbreak of hemolytic-uremic syndrome caused by dry fermented sausage contaminated with Shiga-like toxin-producing Escherichia coli," Journal of Clinical Microbiology, vol. 34, no. 7, pp. 1622-1627, 1996.

[11] L. Sartz, B. De Jong, M. Hjertqvist et al., "An outbreak of Escherichia coli O157:H7 infection in southern Sweden associated with consumption of fermented sausage; aspects of sausage production that increase the risk of contamination," Epidemiology and Infection, vol. 136, no. 3, pp. 370-380, 2008.

[12] B. Schimmer, K. Nygard, H.-M. Eriksen et al., "Outbreak of haemolytic uraemic syndrome in Norway caused by stx2positive Escherichia coli O103:H25 traced to cured mutton sausages," BMC Infectious Diseases, vol. 8, article 41, 2008.

[13] A. L. Holck, L. Axelsson, T. M. Rode et al., "Reduction of verotoxigenic Escherichia coli in production of fermented sausages," Meat Science, vol. 89, no. 3, pp. 286-295, 2011.

[14] D. E. Conner and J. S. Kotrola, "Growth and survival of Escherichia coli O157:H7 under acidic conditions," Applied and Environmental Microbiology, vol. 61, no. 1, pp. 382-385, 1995.

[15] G. J. Leyer, L. L. Wang, and E. A. Johnson, "Acid adaptation of Escherichia coli O157:H7 increases survival in acidic foods," Applied and Environmental Microbiology, vol. 61, no. 10, pp. 3752-3755, 1995.

[16] M. Uyttendaele, I. Taverniers, and J. Debevere, "Effect of stress induced by suboptimal growth factors on survival of Escherichia coli O157:H7," International Journal of Food Microbiology, vol. 66, no. 1-2, pp. 31-37, 2001.

[17] K. W. Arnold and C. W. Kaspar, "Starvation- and stationaryphase-induced acid tolerance in Escherichia coli O157:H7," Applied and Environmental Microbiology, vol. 61, no. 5, pp. 20372039, 1995.

[18] C. Böhnlein, J. Kabisch, D. Meske, C. M. A. P. Franz, and R. Pichner, "Fitness of enterohemorrhagic Escherichia coli (EHEC)/ enteroaggregative E. coli O104: $\mathrm{H} 4$ in comparison to that of EHEC O157: survival studies in food and in vitro," Applied and Environmental Microbiology, vol. 82, no. 21, pp. 6326-6334, 2016.

[19] T. M. Rode, A. Holck, L. Axelsson, M. Høy, and E. Heir, "Shiga toxigenic Escherichia coli show strain dependent reductions under dry-fermented sausage production and post-processing conditions," International Journal of Food Microbiology, vol. 155, no. 3, pp. 227-233, 2012.

[20] E. Heir, A. L. Holck, M. K. Omer et al., "Reduction of verotoxigenic Escherichia coli by process and recipe optimisation in dryfermented sausages," International Journal of Food Microbiology, vol. 141, no. 3, pp. 195-202, 2010.

[21] E. Heir, A. L. Holck, M. K. Omer et al., "Effects of postprocessing treatments on sensory quality and Shiga toxigenic
Escherichia coli reductions in dry-fermented sausages," Meat Science, vol. 94, no. 1, pp. 47-54, 2013.

[22] A. McLeod, I. Måge, E. Heir, L. Axelsson, and A. L. Holck, "Effect of relevant environmental stresses on survival of enterohemorrhagic Escherichia coli in dry-fermented sausage," International Journal of Food Microbiology, vol. 229, pp. 15-23, 2016.

[23] K. Molly, M. V. Woestyne, I. DeSmet, and W. Verstraete, "Validation of the simulator of the human intestinal microbial ecosystem (SHIME) reactor using microorganism-associated activities," Microbial Ecology in Health and Disease, vol. 7, no. 4, pp. 191-200, 1994.

[24] F. Naim, S. Messier, L. Saucier, and G. Piette, "Postprocessing in vitro digestion challenge to evaluate survival of Escherichia coli O157:H7 in fermented dry sausages," Applied and Environmental Microbiology, vol. 70, no. 11, pp. 6637-6642, 2004.

[25] T. Birk, S. Henriksen, K. Müller, T. B. Hansen, and S. Aabo, "Growth potential of exponential- and stationary-phase Salmonella Typhimurium during sausage fermentation," Meat Science, vol. 121, pp. 342-349, 2016.

[26] M. Calicioglu, N. G. Faith, D. R. Buege, and J. B. Luchansky, "Viability of Escherichia coli O157:H7 in fermented semidry low-temperature-cooked beef summer sausage," Journal of Food Protection, vol. 60, no. 10, pp. 1158-1162, 1997.

[27] M. M. Benjamin and A. R. Datta, "Acid tolerance of enterohemorrhagic Escherichia coli," Applied and Environmental Microbiology, vol. 61, no. 4, pp. 1669-1672, 1995.

[28] L. L. Duffy, F. H. Grau, and P. B. Vanderlinde, "Acid resistance of enterohaemorrhagic and generic Escherichia coli associated with foodborne disease and meat," International Journal of Food Microbiology, vol. 60, no. 1, pp. 83-89, 2000.

[29] T. M. Bergholz and T. S. Whittam, "Variation in acid resistance among enterohaemorrhagic Escherichia coli in a simulated gastric environment," Journal of Applied Microbiology, vol. 102, no. 2, pp. 352-362, 2007.

[30] D. C. R. Riordan, G. Duffy, J. J. Sheridan, R. C. Whiting, I. S. Blair, and D. A. McDowell, "Effects of acid adaptation, product $\mathrm{pH}$, and heating on survival of Escherichia coli O157:H7 in pepperoni," Applied and Environmental Microbiology, vol. 66, no. 4, pp. 1726-1729, 2000.

[31] O. J. McQuestin, C. T. Shadbolt, and T. Ross, "Quantification of the relative effects of temperature, $\mathrm{pH}$, and water activity on inactivation of Escherichia coli in fermented meat by metaanalysis," Applied and Environmental Microbiology, vol. 75, no. 22, pp. 6963-6972, 2009. 

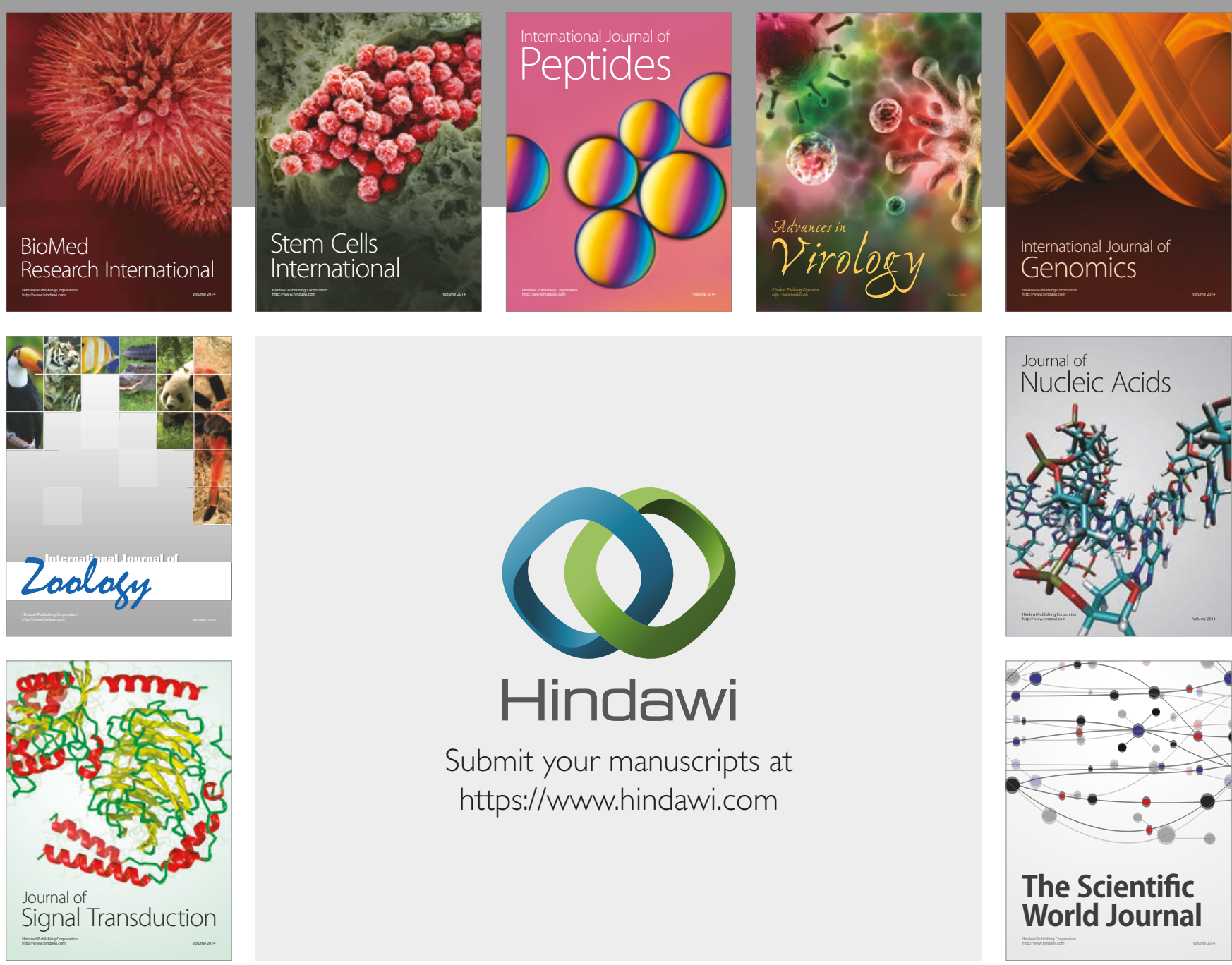

Submit your manuscripts at

https://www.hindawi.com
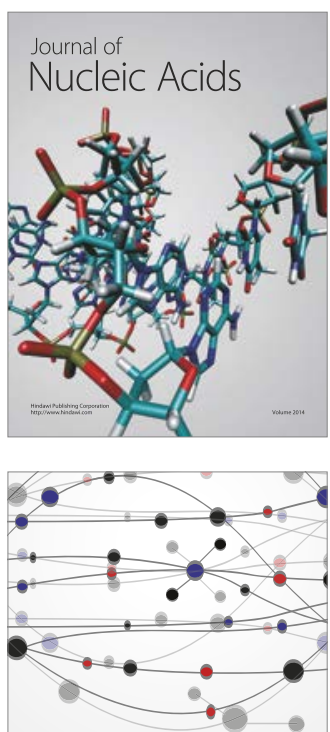

The Scientific World Journal

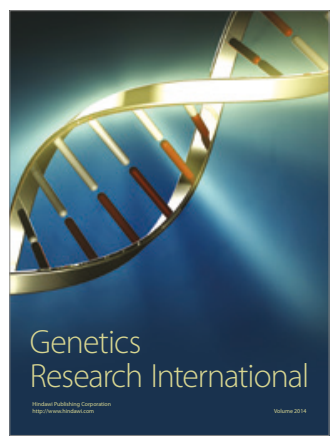

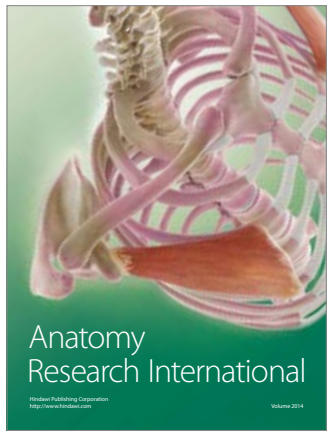

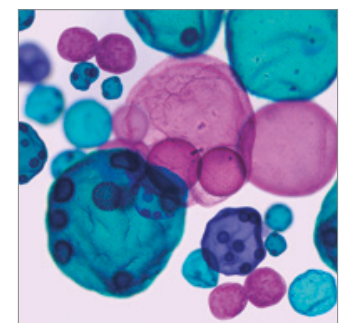

International Journal of Microbiology
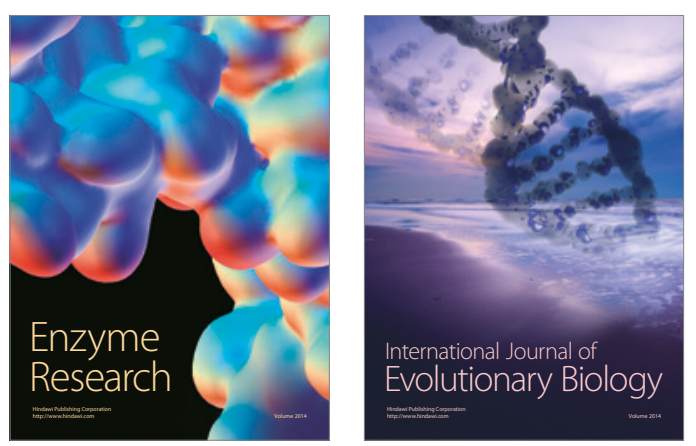
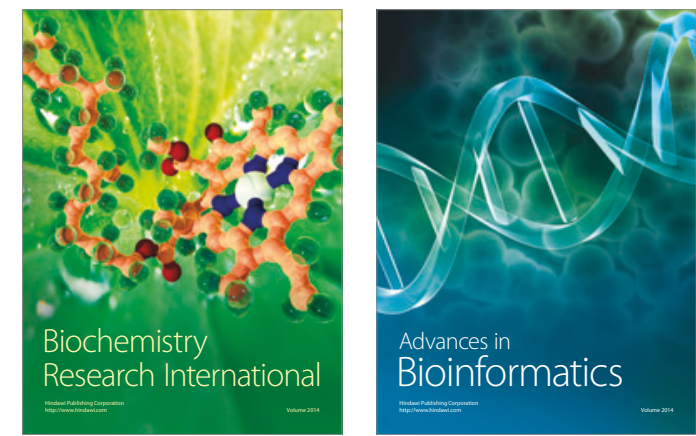

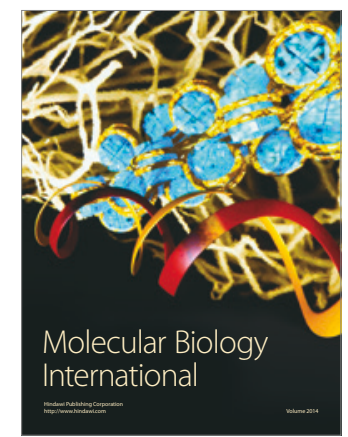

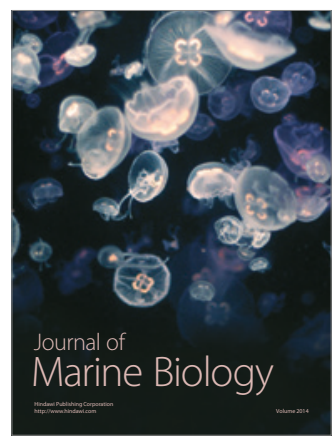

